\title{
Special issue on PODC 2007
}

\section{R. Wattenhofer}

Published online: 19 December 2008

(c) Springer-Verlag 2008

This special issue of Distributed Computing is based on papers that originally appeared, in preliminary and abbreviated form, in the Proceedings of the 26th Annual ACM Symposium on Principles of Distributed Computing (PODC 2007), held in Portland, Oregon on 12-15 August 2007. The papers were chosen by the Program Committee from the 32 full-length papers presented at the Symposium, based on their quality and representation of the range of topics addressed in the Symposium. In addition to being reviewed, in preliminary form, by the Program Committee of PODC 2007, the papers selected for this special issue were subsequently refereed according to the standard practices of Distributed Computing. I wish to thank both the referees and the authors of these papers. Due to time constraints, some of the papers invited to the special issue could not appear in this volume; these will appear in a future volume of this journal.

Roger Wattenhofer Program Committee Chair, PODC 2007

Guest Editor

R. Wattenhofer $(\varangle)$

ETH Zurich, Zurich, Switzerland

e-mail: wattenhofer@tik.ee.ethz.ch 